\title{
DIZER E VER UMA SÉRIE FOTOGRÁFICA DE ROBERT FRANK ${ }^{[1]}$
}

\author{
Rosângela Cherem ${ }^{[2]}$ e Ana Emilia Jung ${ }^{[3]}$
}

\section{RESUMO:}

O presente artigo aborda uma série composta por três fotografias de Robert Frank onde a palavra e a imagem entrelaçam-se numa mesma superfície. Nessas imagens dizer e ver funcionam como inscrições que engendram diferentes mecanismos como se fossem de mesma natureza. Nosso objeto de estudo é a trama significante nascida da intersecção desses elementos e as reflexões inerentes ao campo que funda. Para explorar tais questões do pensamento plástico do fotógrafo recorre-se a uma interlocução com autores que abordam a relação imagem-linguagem pela via do pensamento teórico.

PALAVRAS-CHAVE: fotografia; imagem; linguagem; palavra; Robert Frank.

\section{Introdução ao problema}

Como pensar a fotografia além do ato de colher evidências e seguir pegadas destinadas apenas a compreender um contexto? Considerando a produção artística menos através de um varal cronológico-evolutivo e mais através de questões que envolvem diferentes procedimentos e poéticas, uma resposta possível pode ser avistada na composição serial que recusa o mero encadeamento temporal, buscando um território onde as diferenças e repetições possibilitam reconhecer tanto o caráter inusitado da imagem como produzir novas complexidades e articulações.

Problematizando a repetição na arte como retorno, Didi-Huberman ${ }^{1}$ considera que a obra é sempre portadora de algo já visto que volta subterraneamente como fantasma, atravessando e mesclando diferentes temporalidades pelos arremessos fragmentários da memória. Suspensa entre dois começos, a imagem se refere tanto aquilo que se faz bloco de afecções e sensações num dado momento, como também aquilo que é trazido pelas forças pretéritas que não cessam de retornar como sobrevivência póstuma ou potência associada ao rebatimento do passado no presente, questão que confere à imagem um caráter de espectralidade.

\footnotetext{
${ }^{[1]}$ Projeto vinculado ao Grupo de Estudos de Percepções e Sensibilidades do CEART.

${ }^{[2]}$ Rosângela Miranda Cherem. Professora do Departamento de Artes Plásticas do Centro de Artes e da linha Teoria e História das Artes Visuais do PPGAV, UDESC.

${ }^{[3]}$ Mestranda matriculada no Programa de Pós-Graduação em Artes Visuais da UDESC, na linha Teoria e História das Artes Visuais.
} 
$\mathrm{Na}$ contradança da cronologia, as imagens artísticas podem ser pensadas como portadoras de impurezas e descontinuidades temporais. Para alcançá-las é preciso recorrer aos procedimentos de montagem, construindo séries capazes de revelar a sobrevivência de um recalque. Pelos efeitos de cintilação e em ocasiões de proximidade empática acontece uma espécie de dobra temporal, através da qual surge o sintoma. Operando em des-tempos, não se trata nem de um conceito semiológico, nem clínico, mas de uma noção que recusa submissão ao tempo eucrônico para ser alcançada como anacronismo, ou seja, aquilo que, interrompendo o fluxo regular das coisas, constitui-se como latência que conjuga diferente-semelhante, proximidadedistância, imobilidade-aceleração.

Desdobrando esta abordagem parece conveniente considerar o conceito psicanalítico de alteração $o^{2}$, através do qual a criança como o artista elaboram o assassinato da coisa e constroem sua simbolização através da metamorfose das formas, sendo esta mesma simbolização inerente à mudança de um estado para outro e equivalente a um signo lingüístico constantemente esvaziado e re-significado. $\mathrm{Na}$ relação próximo-distante, o recalque é aquilo que, não podendo calar, retorna como desvio e faz despontar a criação como elaboração da perda e do luto, ou seja um trabalho de esquecimento que se mantém como derivação infinita da matéria.

Por sua vez, em clave pós-estruturalista, repetir não tem equivalente nem semelhante, pois repetir é sempre um irrecomeçável. Assim, Deleuze ${ }^{3}$ assinala que a diferença se constitui como aquilo que nem está subordinado ao idêntico, nem é sua negação, nem se refere à oposição nem se constitui como contradição, visto que se trata de preservar a potência como poder do diverso. Distinguindo a repetição da simples generalidade, considera que enquanto uma obedece leis com permanências e variáveis, possibilitando que um termo possa ser traduzido por outro e o particular possa ser reposto e substituído, posto que é indeterminado e indiferenciado, a outra se coloca como vibração secreta.

\footnotetext{
${ }^{1}$ DIDI-HUBERMAN, Georges. Ante el Tempo: História del arte y anacronismo de las imagenes. Buenos Aires: Adriana Hidalgo Editora, 2006.

${ }^{2}$ FREUD, Sigmund. Além do Princípio do prazer. Coleção Obras completas, vl XXVIII. R.J.:Ed. Imago, 1976.

${ }^{3}$ DELEUZE, Gilles. Diferença e Repetição. R.J.: Graal, 2006
} 
Quando a repetição e o retorno tornam-se potência, gravitações e saltos são inventados para agir em função daquilo que não se é e nem se tem. Se não se pode trocar a alma e se os duplos como os ecos não possuem equivalência ou semelhança, do mesmo modo não existe acréscimo numa segunda ou terceira vez, elevando-se a primeira vez à enésima potência. Sendo a arte o lugar onde as diferentes repetições coexistem, a repetição é diferença sem conceito, não porque se constitui como reprodução do mesmo e sim porque é arremesso em direção ao outro. Assim, os disfarces revelam sintomas que operam por deslocamento, potencializando uma realidade mais profunda, impossível tanto de reter como de alcançar.

\section{Palavra e mimetismo}

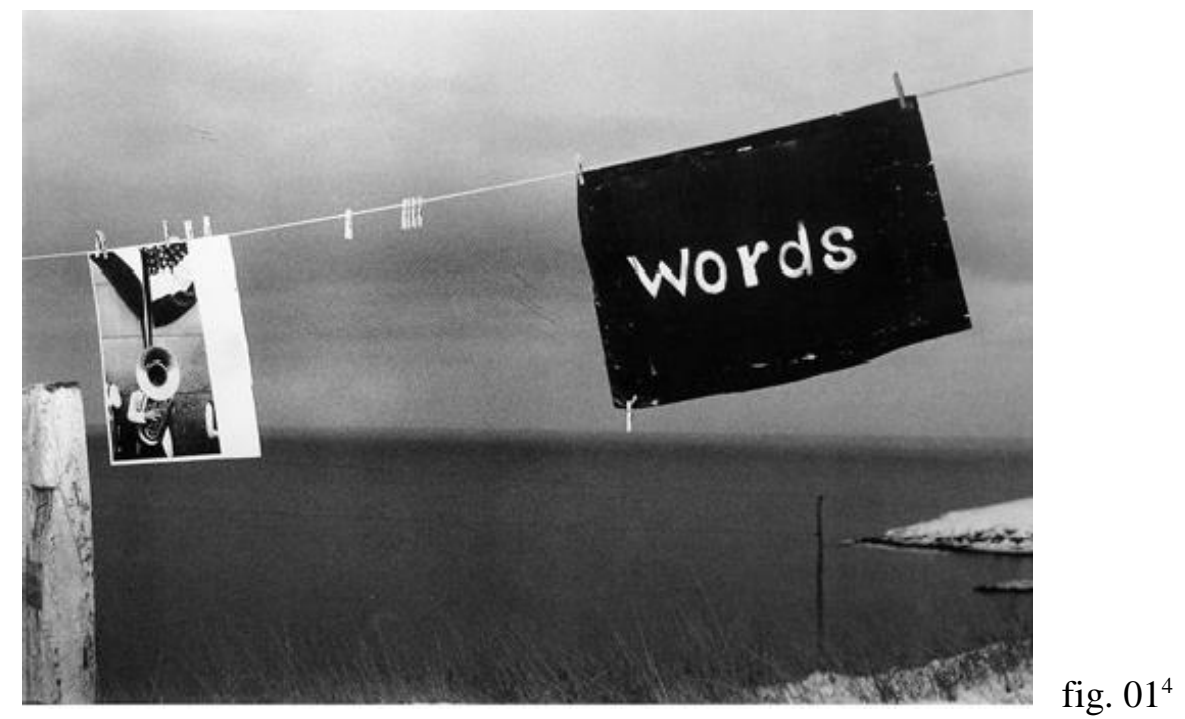

Observemos esta foto de Robert Frank datada de 1972 e intitulada Words. Aparentemente numa paisagem onde se avista um mar calmo e um céu nublado, destaca-se um varal, onde grampos de roupa suspendem e suportam dois pedaços de tecidos em que a estampa de um é também a fotografia de um instrumento musical, atrás do qual um rosto se oculta e um diminuto tronco quase desaparece. Ao fundo e acima desta mesma figura surge a ponta da bandeira americana, tão fragmentada e

\footnotetext{
${ }^{4}$ FRANK, Robert. The Lines of My Hand, 2 ed. Pantheon Books, N.Y., 1982.
} 
distante como o corpo humano. Mas o que se destaca é o outro pedaço de tecido cujas letras assinalam a palavra palavra. Nesta tautologia o que parece se ocultar é um jogo mimético, mas que toma o mimetismo por um modo muito parecido com a compreensão de Roger Caillois, autor surrealista que escreveu sobre o perturbador fenômeno da psicastenia.

Abordando a homocromia como o fenômeno em que a imagem retiniana é transposta para a pele através da ação automática produzida pela excitação luminosa nas células cromóforas, o que por sua vez resulta na produção de similitude de certos animais com o outro e com o meio, procurou pensar sobre esta circunstância também conhecida como telefotografia, recusando-se a simplificá-la, quer pela explicação finalista da religião quer pelo mecanicismo científico. Uma vez que restos de animal mimetizado podem ser encontrados nas vísceras do animal predador, tal fenômeno deveria ser considerado menos como uma defesa para fins de preservação e mais como um instinto de abandono, posto que o olho animal pode ser pensado como um veículo de fascinação que ultrapassa as soluções dadas tanto pelo acaso como pela adaptação.

Ainda que sofisticada, a imitação não deixaria de ser uma armadilha e a distinção do organismo em relação ao meio estaria comprometida por um distúrbio da percepção espacial que poderia ser sintetizado pela afirmação "sei onde estou, mas não me sinto no lugar onde me encontro." ${ }^{5}$ Nesta tendência à imobilidade e ao inorgânico o que se confirma é uma economia de dispêndio, verificando-se o mesmo no conhecimento e na arte, cujos movimentos mais atraentes acabam por agir como força final, resultando numa espécie de uniformidade ou anulação que conduz ao inanimado. Desse modo, para Caillois em sua atração inescapável pelo meio e o outro, o olho como dispositivo de sobrevivência se transforma em fatal armadilha. Assim, no raciocínio elaborado em tempos de entre-guerras, pode-se reconhecer um território de investigações que colocam em xeque os conhecimentos fundados na certeza retiniana e nos preceitos da razão como instrumento de progresso e emancipação.

\footnotetext{
${ }^{5}$ CAILLOIS, Roger. Mimetismo e psicastenia legendária. Revista Che Voui, ano $1, \mathrm{n}^{\circ}$, Cooperativa Cultural Jacques Lacan, Porto Alegre: 1986.
} 


\section{Palavra e labirinto}

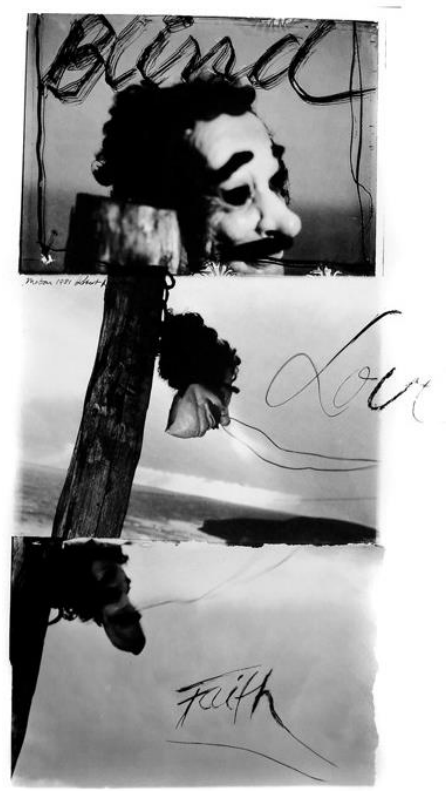

fig. $02^{6}$

Reparemos agora a fotografia intitulada Blind, Love, Faith de 1981. Nela Robert Frank arranha a emulsão da superfície da gelatina de prata da fotografia. Em destaque a caligrafia vulnerável que aponta uma certa descontinuidade de traço que passeia do fino ao grosso, repetindo-se reiteradamente num mesmo trecho diversas vezes até somar-se um pequeno borrão; num outro instante, o traço torna-se esvanecente a ponto de diluir-se no fundo. O tríptico vertical é construído a partir de uma certa repetição de cena onde as paisagens se alternam em distâncias - perto, longe, nem tão perto - causando o ritmo imperfeito na dinâmica da imagem. $O$ número ímpar carrega a sina do número de ouro: três desejos, nascimento, vida e morte; ou todos os simbolismos a que se possa remetê-lo, impossível não deduzir. As três palavras escritas começam em letras maiúsculas e sugerem três inícios: Cegueira, Amor, Fé.

Com o que se parece esta foto? Com nada a não ser com ela mesmo: jogo de linhas e figuras que não querem reapresentar o mundo mas pensar ludicamente sua

\footnotetext{
${ }^{6}$ FRANK, Robert. The Lines of My Hand, 2 ed. Pantheon Books, N.Y., 1982.
} 
representação, construindo um campo de figuras estranhas e familiares, funcionando como testemunhas que tornam a vida natural suspeita. Abordando o barroco como função operatória, Deleuze considera a questão a partir de Leibniz, o qual remete à idéia da mônada como casa em cujo andar inferior caberiam os organismos e amontoados viventes, enquanto no andar de cima caberia a alma, caracterizada como o próprio espaço sem janelas e alheio à exterioridade. Todavia reconhecendo a divisão infinita e as porções contaminadas e circunvizinhas, recusa a mera compartimentalização em proveito de labirintos de continuidades, cuja menor unidade é a própria dobra em incessante movimento.

Em contraposição ao quadro como modelo exterior e em conformidade com a perspectiva renascentista da janela, a noção leibnizeana reafirma a matéria como uma vastidão sempre exterior e uma profundidade infinita, lembrando a virtualidade incessante do teatro das matérias e destacando no acúmulo das espessuras e na duplicidade das superfícies um mundo que não possui existência fora delas. Para Leibniz como para Deleuze, trata-se de compreender o pensamento não como modelo ótico preciso e sim como uma geometria situada num momento de crise: "antes de o mundo perder seus princípios, o esplêndido momento em que alguma coisa se mantém em vez do nada, em que responde à miséria do mundo com o excesso de princípios."

Por sua vez, se consideramos as imagens fotográficas de Robert Frank como um modo de olhar uma cultura em crise, pode-se também recorrer a Maurice Blanchot. Inscrito na tradição da literatura que problematiza a linguagem, o autor de A conversa infinita problematiza a natureza da imagem e suas complexidades, assinalando que ver é esquecer de falar e dizer não é ver, pois ver é perceber através de distância interminável. Mas, se a figura como a palavra toma a coisa por onde ela não é, é porque a linguagem como substância não representa nem revela, nem cobre nem descobre, apenas encobre. Não sendo nem comunicação e nem expressão, é sempre desvio e por este motivo escapa das convenções e da lógica cotidiana desfazendo o curso em que nos instalamos e recusando-se a ser reduzida à expressão subjetiva do autor. Se a linguagem é fonte de enganos é porque não reside nem naquilo que vemos nem naquilo que dizemos, mas habita um ponto movente e poroso entre o aquém e o além, constituindo-se como distância que faz avançar, quer pela memória quer pela imaginação artística. Nessa perspectiva as possibilidades mais

\footnotetext{
${ }^{7}$ DELEUZE, Gilles. A dobra. Leibniz e o barroco. S.P.: Papirus, 2005, 2a ed, p. 118
} 
radicais da linguagem se movimentam em direção a um vazio ou exterioridade. Resta perguntar se, sendo a visão invisível e o que é desaparece naquilo que o nomeia, também o que é visto desaparece naquilo que assinala?

A imagem aqui em questão parece apontar para a reflexão de Blanchot, em relação ao fato de que a palavra transgride e desorienta, enquanto a visão está calcada dentro dos limites de um horizonte. Ver supõe uma apreensão do tangível baseada na tradição ocidental do olhar e que não prescinde da presença da luz ou da ameaça de sua ausência, isto quer dizer que ver depende de uma realidade palpável, de um condicionamento construído culturalmente. Talvez, para Robert Frank, seja essa questão a que o impossibilita de abandonar-se na crença da fotografia única, direta, sem manipulação. Os elementos intrínsecos da fotografia como foco, enquadramento, ponto-de-vista, profundidade de campo e velocidade do obturador, são todos eles construídos a partir dessa lógica ótica que depende do olho fisiológico e de um aparato tecnológico construído nessas bases. A obra de Robert Frank abre mão da potencia desse mecanismo fotográfico e para elaborar uma operação mais calcada na experiência fenomenológica do que na fisiologia. Sua proposta é a destruição dos elementos descritivos da imagem que por sua vez, consequentemente, põe em questão o estigma da objetividade do foto-realismo.

Se para Blanchot, "ver é talvez esquecer de falar e falar é puxar do fundo da palavra o esquecimento que é o inesgotável"8, Robert Frank soma essas duas inscrições e constrói imagens. Em seu modo de pensar, a imagem se contrapõe a visão no sentido que acontece não no confronto com a realidade, mas num segundo momento, no desdobramento inicial quando a visão já se faz figura. Enquanto a visão distancia e aproxima o visível e o falar desenreda a matéria incessante da qual somos feitos, a imagem é a que habita a tenra fronteira entre eles e joga no campo além do visível e invisível, a imagem é da ordem do fascínio.

\section{Palavra e vazio}

\footnotetext{
${ }^{8}$ BLANCHOT, Maurice. A conversa infinita- a palavra plural. vol.01. São Paulo: escuta, 2001. p.68.
} 
Tomemos uma outra fotografia de Robert Frank, executada em 1980 e intitulada Pour la fille. Observando seu caráter ornamental, trabalhado por uma espécie de exímio joalheiro que produz algo tão minucioso e secreto que apenas através de uma fração e só raramente este esforço pode ser percebido. Por que cria estas superfícies, o que elas guardam ou a qual vazio remetem? Até onde é possível compreender seu preciosismo ou por que o faz se sabe que é dispêndio?

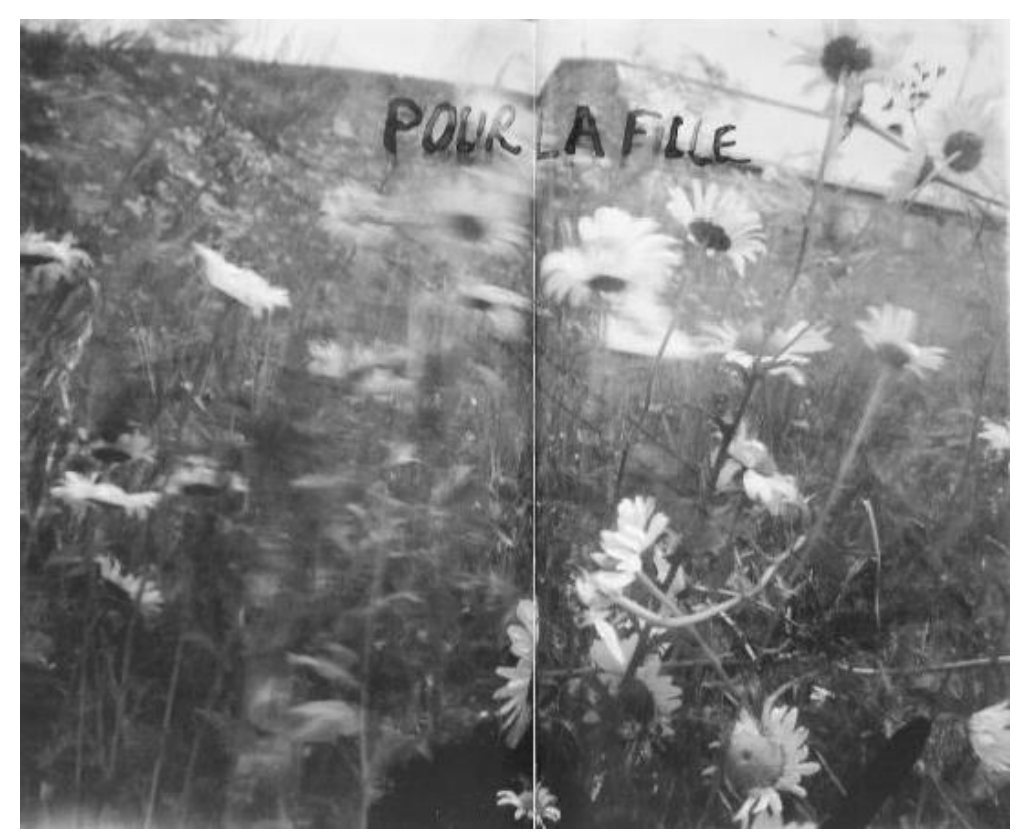

figura $03^{9}$

Nesta foto o silêncio da imagem é cortado pelo gesto indissolúvel que une palavra e imagem, e cujas as letras em maiúsculas são imperativas na intenção: Para uma jovem. No espaço entre o que se vê e o que se diz, o fantasma, presença inefável da obra, sobrepõe-se ao jogo de signos. Palavra que é signo e conteúdo, palavra que é ação e enunciação, palavra que denuncia a essência do gesto, a intenção. Questão que, ao mesmo tempo, funda e solapa o fenômeno do olhar, emoldurando ou preenchendo uma ausência, a imagem ali contida parece dirigir-se intimamente a quem para ela se volta, ao mesmo tempo em que remetem ao vazio, ao exterior e ao indefinido, "fundo sórdido sobre o qual ela continua afirmando as coisas em seu desaparecimento." 10 Assim o que ela preenche refere-se a uma distância indeterminada da forma, ou seja, a

\footnotetext{
${ }^{9}$ FRANK, Robert. The Lines of My Hand, 2 ed. Pantheon Books, N.Y., 1982.

${ }^{10}$ BLANCHOT, Maurice. O espaço literário. R.J.: Ed. Rocco, 1987, p. 256
} 
uma sorte de humanização do informe, retirando a obscuridade do destino em sua essência, que é a de ser sombra.

Pensemos especialmente nas estelas funerárias, posto que ali se torna mais presente a dimensão presença-ausência inapreensível e inatural da imagem, assinalando um cadáver "na calma absoluta do que encontrou seu lugar" "11, ao mesmo tempo em que suspende a relação absoluta com ele. Aqui e em parte alguma, eis o lugar do morto que se une ao fundo, situando num antemundo, aquém- além eterno onde a ação está impossibilitada de voltar à superfície do que restou. Imponente e soberbo, ser que triunfa e se exprime com o recurso inacessível do longínquo, o corpo morto surge como imagem da aparição original em sua mais elementar e perturbadora estranheza, remetendo ao fato de que a fixidez da imagem, como a do cadáver, "é a posição do que permanece porque lhe falta lugar." 12 Transportado para um local situável e simbólico, o despojo passa a pertencer também a um lugar impessoal e neutro, confirmando-se como aquilo com que os viventes tentam contornar a mais inescapável condição: "íntima é a imagem porque ela faz de nossa intimidade uma potência externa a que nos submetemos passivamente: fora de nós, no recuo do mundo que ela provoca, situa-se desgarrada e brilhante, a profundidade de nossas paixões." ${ }^{13}$

Para Blanchot, a linguagem como a imagem não representa o mundo exterior mas funda sua própria realidade. É uma forma de pensamento que está calcada numa busca interior, que "questiona e ultrapassa as verdades de cada época histórica"14. O autor chama de experiência do fora o espaço potencial da escrita como dimensão de existência, para além do previsível e do conhecido. Nessa busca e criação de mundo, a palavra é o recurso que materializa o movimento em direção a um centro que jamais se alcança. A palavra errante, sem finalidade, manifesta-se em si mesma. Quando o autor pensa a relação entre o falar e o ver pensa a linguagem que se desvia do caminho preciso e alcança uma ambigüidade inquietante, assim, a palavra obscura, da qual tratamos aqui, abre um leque de percursos na dimensão de um vir a ser. Palavra "mais franca em seu viés, sempre persistindo na interrupção, sempre chamando o desvio e assim nos mantendo em suspenso entre o visível e o invisível, ou aquém de

\footnotetext{
${ }^{11}$ BLANCHOT, Maurice. O espaço literário. R.J.: Ed. Rocco, 1987. p. 258

12 Ibidem, p. 260

13 Ibidem, p. 263

${ }^{14}$ LEVY, Tatiana Salem. A experiência do fora. R.J.: Ed. Relume Dumará, 2003. p.14.
} 
um e de outro." ${ }^{\prime 15}$ Palavra desnuda que se apresenta como presença latente e manifestase além da fórmula e do jogo, é traço no mundo. Blanchot lembra que o estilete era o instrumento da escrita, o que remete a inscrição da palavra a uma operação cortante, diz ele: "O jogo da etimologia corrente faz da escrita um corte, um dilaceramento, uma crise. $" 16$

Assinalando uma espécie de cenografia que problematiza o espetáculo do mundo através de um através, um fundo, Robert Frank aborda a fotografia como um jogo de opacidade e remete a um território que ultrapassa o campo da visão. Simulando uma unidade estas figuras remetem à dramaturgia do invisível obtida pela eficácia da imagem desfazendo a evidência do mundo e produzindo uma confusão do código visual, onde a centralidade retiniana é alterada para pensar a existência, através dos vestígios por ela deixados e que a elas remetem. Encenando o como se nada fosse a não ser a vida própria do objeto mesmo, o artista recorre a certos procedimentos destinados a reduzir, fazer desaparecer ou confundir o gesto fotográfico, conduzindo ao nada mais que, inquietando o campo do espectador e produzindo um rasgo que alcança e atinge aquele que se encontra diante da obra.

Deparando-se com uma espécie de armadilha destinada a demonstrar o quanto o olho é refém do olhar, tais operações são semelhantes a uma charada associada à certeza documental e à evidência da verdade, mas que instala precisamente nesse ponto as confusões entre o estranho e o familiar. Exagerando a aparência do real, o olhar é conduzido à constatação das irresoluções que se escondem sob a aparente precisão e que os olhos são sempre portadores de uma névoa. Se não existe um olhar complemente inocente, pois sempre vemos através dos véus que somos portadores, afirma-se a compreensão de que a fotografia como obra de arte é somente um jogo, posto que o artista pode apenas contornar aquilo que jamais alcança, nada mais fazendo do que figurar a experiência do vazio a partir de desarranjos e desencontros na vã tentativa de reencontrar a coisa como paradoxo da criação.

\footnotetext{
${ }^{15}$ BLANCHOT, Maurice. A conversa infinita- a palavra plural. vol.01. São Paulo: escuta, 2001. p.70.

${ }^{16}$ Ibidem, p. 66.
} 


\section{REFERÊNCIAS BIBLIOGRÁFICAS}

BLANCHOT, Maurice. A conversa infinita- a palavra plural. vol.01. São Paulo: escuta, 2001.

O espaço literário. R.J.: Ed. Rocco, 1987.

CAILLOIS, Roger. Mimetismo e psicastenia legendária. Revista Che Voui, ano 1, nº, Cooperativa Cultural Jacques Lacan, Porto Alegre: 1986.

DELEUZE, Gilles. A dobra. Leibniz e o barroco. $2^{\text {a }}$ ed. S.P.: Papirus, 2005.

Diferença e Repetição. R.J.: Graal, 2006

DIDI-HUBERMAN, Georges. Ante el Tempo: História del arte y anacronismo de las imagenes. Buenos Aires: Adriana Hidalgo Editora, 2006.

FREUD, Sigmund. Além do Princípio do prazer. Coleção Obras completas, vl XXVIII. R.J.:Ed. Imago,1976.

LEVY, Tatiana Salem. A experiência do fora. R.J.: Ed. Relume Dumará, 2003. 